\title{
The insulin-like growth factor-I receptor kinase inhibitor NVP-ADW742 sensitizes medulloblastoma to the effects of chemotherapy
}

\author{
HUI ZHOU ${ }^{1 *}$, JING RAO $^{2 *}$, JIAN LIN $^{1}$, BO YIN $^{1}$, HANSONG SHENG ${ }^{1}$, \\ FENGCHUN LIN ${ }^{1}$, NU ZHANG ${ }^{1}$ and LIN YANG ${ }^{2}$ \\ ${ }^{1}$ Department of Neurosurgery, The 2nd Affiliated Hospital of Wenzhou Medical College, Wenzhou 325000; \\ ${ }^{2}$ Department of Neurosurgery, Union Hospital, Tongji Medical College, Huazhong University \\ of Science and Technology, Wuhan 430022, P.R. China
}

Received December 20, 2010; Accepted February 7, 2011

DOI: 10.3892/or.2011.1233

\begin{abstract}
Medulloblastoma is the most common malignant tumor of the central nervous system in children. The insulin-like growth factor-I receptor (IGF-IR) is an important growth factor for medulloblastoma. The novel IGF-I receptor (IGF-IR) kinase inhibitor NVP-ADW742 has in vitro activity against tumors. Daoy cells were treated with NVP-ADW742 combined with temozolomide, which is commonly used in the chemotherapy of medulloblastoma. The effects on proliferation were assayed by CCK- 8 assay. Cell cycle status and apoptosis were assayed by FACS analysis. The IGF-IR signaling pathway was analyzed by $\mathrm{RT}^{2}$ Profiler $^{\mathrm{TM}}$ PCR arrays and Western blotting. NVP-ADW742 inhibited IGF-IRmediated proliferation with an $\mathrm{IC}_{50}$ of $11.12 \mu \mathrm{mol} / 1$. The PCR array data suggested that 14 genes were down-regulated at the mRNA level after NVP-ADW742 treatment. Western blot analysis suggested that NVP-ADW742 induced early suppression of Akt, P38 and GSK-3 $\beta$ phosphorylation, as well as a decrease in the intracellular levels of PI3K, Akt, P38, GSK-3 $\beta$ and Bcl-2. Combined with NVP-ADW742 (2 $\mu \mathrm{mol} / \mathrm{l}), \mathrm{IC}_{50}$ of Daoy to temozolomide was decreased from 452.12 to $256.81 \mu \mathrm{mol} / 1$. Cell apoptosis was enhanced from $16.18 \pm 2.47 \%$ to $23.20 \pm 2.80 \%$. G phase arrest was also found
\end{abstract}

Correspondence to: Dr Nu Zhang, Department of Neurosurgery, The 2nd Affiliated Hospital of Wenzhou Medical College, 109 Xueyuan Street, Wenzhou 325000, P.R. China

E-mail: zhangnu65@hotmail.com

Dr Lin Yang, Department of Neurosurgery, Union Hospital, Tongji Medical College, Huazhong University of Science and Technology, 1277 Jiefang Avenue, Wuhan 430022, P.R. China

E-mail: linyang@mail.hust.edu.cn

*Contributed equally

Key words: medulloblastoman the insulin-like growth factor-I receptor, NVP-ADW742, temozolomide in both the temozolomide alone group and the temozolomide combined with NVP-ADW742 group. NVP-ADW742 inhibited the activation of PI3K, Akt, P38 and GSK-3 $\beta$ caused by temozolomide. NVP-ADW742 enhanced the chemosensitivity of Daoy to temozolomide in vitro, as a potent anti-tumor agent highly selective against IGF-IR.

\section{Introduction}

Medulloblastoma is the most common malignant tumor of central nervous system in children. Medulloblastoma represents nearly $25 \%$ of all paediatric intracranial neoplasms. This highly malignant tumor arises from the cerebellum and affects predominantly children between the ages of 5 and 15. Patients with medulloblastoma are currently staged as average-risk or poor-risk on the basis of clinical findings. With current multimodality therapy including surgery, radiotherapy and chemotherapy, nearly $90 \%$ of children with average-risk, non-disseminated medulloblastoma have 5-year event-free survival, and those with high-risk disease have a 60-65\% survival rate; however, the outcome for younger children, particularly infants, is worse. Attempts to further reduce the morbidity and mortality associated with medulloblastoma have been restricted by the toxicity of conventional treatments and the infiltrative nature of the disease. Over the past decade, new discoveries in molecular biology have revealed new insights into the signaling pathways regulating medulloblastoma. Molecular biology has changed our understanding of medulloblastoma and has implications for diagnostic stratification and treatment. As newer biological agents are translated from the lab to the bedside, clinicians need to understand the fundamental signaling pathways that are targeted during therapy. Greater understanding of the molecular biology of medulloblastoma is needed so that more children can be cured or have an improved quality of life $(1,2)$.

Although the aetiology of medulloblastoma has not been elucidated, several reports show that the insulin-like growth factor-I receptor (IGF-IR) signaling system is highly activated in medulloblastoma cell lines, medulloblastoma animal models and medulloblastoma biopsies, suggesting its contri- 
bution to the development, progression and the drug resistance of these tumors (3-5). IGF-I is a peptide hormone critical for growth, development and oncogenic transformation. Its effects are exerted through the IGF-I receptor (IGF-IR), a member of the insulin receptor subclass of receptor tyrosine kinases. In the central nervous system (CNS), IGF-IR has been implicated in fetal and postnatal growth and development of the brain as well as in brain tumors. IGF-IR is a multifunctional membrane-associated tyrosine kinase that sends a mitogenic signal, protects normal and tumor cells from apoptosis (6), may induce cell differentiation (7), and plays an important role in the maintenance of the transformed phenotype by different viral and cellular oncogenes (8). Collectively, these observations prompted the investigation of different strategies to impair the function of IGF-IR as a potential therapeutic tool, which by compromising growth and survival of medulloblastoma cells could supplement conventional therapeutic regiments against these malignant neoplasms of childhood.

The purpose of this study was to determine whether the novel IGF-I receptor (IGF-IR) kinase inhibitor, NVP-ADW742, sensitizes medulloblastoma cell line to temozolomide (TMZ), which is commonly used in the treatment of medulloblastoma.

\section{Materials and methods}

Compounds. NVP-ADW742 was kindly provided by Novartis Pharma AG (Basel, Switzerland). Stock solutions were made in $100 \%$ DMSO (Sigma Chemical Co., St. Louis, MO) and diluted with culture media before use. The final DMSO concentration in all cultures, including vehicle controls, was $0.1 \%$. Temozolomide was kindly provided by Jiangsu TaslyDiyi Pharmaceutical Co., Ltd. (Jiangsu, China). Stock solutions were made in $100 \%$ DMSO (Sigma Chemical Co.) and diluted with culture media before use. The final DMSO concentration in all cultures, including vehicle controls, was $0.1 \%$. IGF-I was purchased from R\&D Systems (Minneapolis, MN). Stock solutions were made in sterile PBS and diluted with culture media before use. Dulbecco's modified Eagle's medium (DMEM), fetal bovine serum (FBS) were all purchased from Gibco-Invitrogen (Grand Island, NY, USA).

Cell culture. Human medulloblastoma cell line Daoy was obtained from ATCC and maintained in DMEM medium (Gibco) supplemented with $10 \%$ fetal bovine serum (Gibco) and incubated at $37^{\circ} \mathrm{C}$ in a humidified incubator with $5 \%$ $\mathrm{CO}_{2}$.

Cell proliferation analysis. Cell proliferation assay was performed with CCK-8, according to the manufacturer's instructions. In brief, Daoy cells were seeded in a 96-well plate at density of $1 \times 10^{6}$ cells $/ \mathrm{ml}$. The following day, medium was changed in DMEM plus $10 \%$ FBS without or with agents. Cells were incubated for $72 \mathrm{~h}$ and CCK-8 (Cell Counting Kit-8, Dojindo Laboratories) was used as the manufacturer's instructions. Extinction was measured at $450 \mathrm{nM}$ and reference extinction subtracted. Each experiment was performed in triplicate and repeated three times.

Cell cycle analysis. Daoy cells were seeded in 6-well cell plates in DMEM plus $10 \%$ FBS. The following day, medium was changed in DMEM plus 10\% FBS without or with agents. Cells were collected after $72 \mathrm{~h}$. Cell pellets were washed with cold phosphate-buffered saline (PBS) and were fixed in 70\% ethanol to determine cell cycle distribution. Cell suspensions were washed with PBS and resuspended in $0.1 \%$ sodium citrate, $0.1 \%$ Triton $\mathrm{X}-100$ and $50 \mu \mathrm{g} / \mathrm{ml}$ propidium iodide (PI) for $20 \mathrm{~min}$ at room temperature in the presence of $250 \mu \mathrm{g} / \mathrm{l}$ RNAse. Mono-variate distributions of cell number vs. DNA content (PI) were analyzed using a BD FACS Calibur flow cytometer. At least 20000 events were collected in each histogram. Cell cycle analysis was performed using the BD Cell Quest Pro Acquisition and ModFit Mac V3.0 analysis software (BD Biosciences, San Jose, CA).

Apoptosis analysis. Daoy cells were seeded in 6-well cell plates in DMEM plus $10 \%$ FBS. The following day, medium was changed in DMEM plus $10 \%$ FBS without or with agents. Cells were collected after $72 \mathrm{~h}$. Detection and quantification of apoptotic cells was obtained by flow cytometric analysis of Annexin V-FITC-labeled cells. This test was done according to the manufacturer's instructions.

PCR array analysis. Daoy cells were seeded in 6-well cell plates in DMEM plus $10 \%$ FBS. The following day, medium was changed in DMEM plus $10 \%$ FBS without (control) or with NVP-ADW742 (2 $\mu \mathrm{mol} / \mathrm{l})$. Total RNA was extracted from cells with TRIzol (Invitrogen) after $72 \mathrm{~h}$, according to the manufacturer's instructions. The total RNA extracted was treated by RNeasy ${ }^{\circledR}$ MinElute ${ }^{\mathrm{TM}}$ Cleanup Kit (Qiagen, USA) for removal of contaminating DNA, following the protocols provided. After assessing RNA yield and quality, reverse transcription was performed with a SuperScript.III Reverse Transcriptase (Invitrogen), following the instructions provided. Then samples were tested by $\mathrm{RT}^{2}$ Profiler $^{\mathrm{TM}}$ PCR Array Human Insulin Signaling Pathway (SA Biosciences Corp., USA). Data were analyzed by the $\Delta \Delta \mathrm{Ct}$ method. The experiment was performed in triplicate and repeated three times.

Western blot analysis. To analyze the effects of NVP-ADW742 compound on IGF-IR signaling pathway of Daoy, starved cells were pretreated for $2 \mathrm{~h}$ with NVP-ADW742 (0.5-2 $\mu \mathrm{mol} / \mathrm{l})$ and then exposed to IGF-I $(10 \mathrm{ng} / \mathrm{ml})$ for $48 \mathrm{~h}$. In a second experiment, we followed NVP-ADW742 inhibitory effects on IGF-IR signaling pathways by exposing Daoy to NVP-ADW742 ( $2 \mu \mathrm{mol} / \mathrm{l}$ ) for $1-48 \mathrm{~h}$ in standard medium. To figure out the mechanism of IGF-I R signaling pathway in the temozolomide resistance, Daoy cells were synchronized in 6-well cell plates in DMEM plus $10 \% \mathrm{FBS}$, followed by the exposure to temozolomide $(100 \mu \mathrm{mol} / \mathrm{l})$ with or without NVP-ADW742 $(2 \mu \mathrm{mol} / \mathrm{l})$ for $72 \mathrm{~h}$. We measured the protein profile by Western blot analysis. The cells were lysed using M-PER lysis buffer (Pierce, USA). Protein was extracted and quantified using a BCA assay kit (Pierce). A total of $50 \mu \mathrm{g}$ of each sample was heated at $95^{\circ} \mathrm{C}$ for $10 \mathrm{~min}$ and loaded into $10 \%$ gel. Under denaturating conditions and transferred onto PVDF membrane. Membranes were blocked in 5\% non-fat dry milk TBS-T or $5 \%$ BSA TBS-T for 1-1.5 h, incubated with primary antibodies [anti-PI3K, dilution 1:1000; anti-Akt, dilution 1:1000; anti-phospho-Akt (Thr180/Thr182), dilution 1:1000; anti-P38 MAPK, dilution 1:1000; anti-phospho-P38 MAPK (Ser473), 


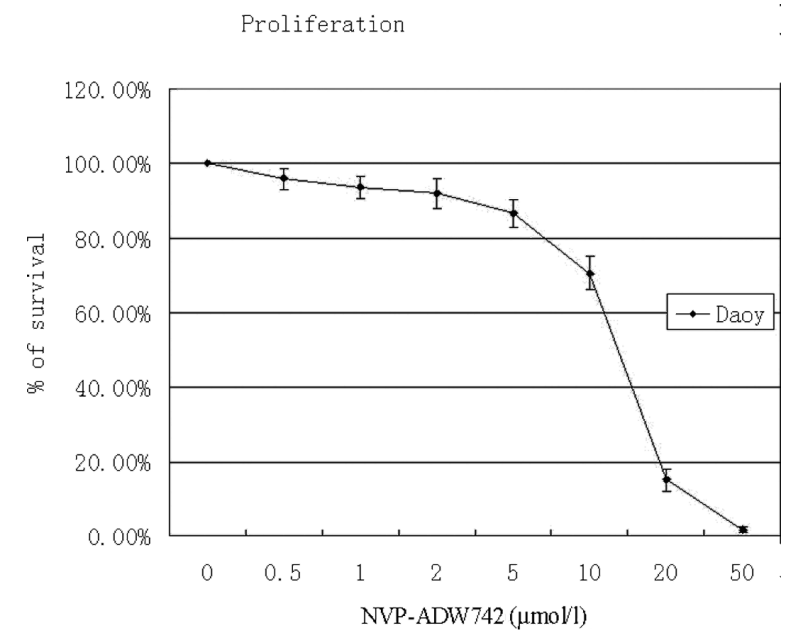

Figure 1. The effects of NVP-ADW742 treatment on proliferation were assayed by CCK- 8 assay. Cells were cultured for $72 \mathrm{~h}$ in the indicated concentrations of NVP-ADW742, from 0.5 to $50 \mu \mathrm{mol} / \mathrm{l}$. The CCK-8 assay was performed successively. NVP-ADW742 inhibited the cell proliferation in Daoy cells. The results were the means $\pm \mathrm{SD}$ of three separate experiments and each sample was performed in triplicate $(n=3, P<0.01)$.

dilution 1:1000; anti-GSK-3 $\beta$, dilution 1:1000; anti-phosphoGSK-3 $\beta$ (Ser9), dilution 1:1000; anti-Bcl-2, dilution 1:500; anti- $\beta$-actin, dilution 1:1000; (Cell Signaling Technology, Beverly, MA)] overnight, and then incubated with secondary anti-rabbit antibody conjugated to horseradish peroxidase (Cell Signaling Technology, Beverly, MA; dilution 1:2000) for
$1 \mathrm{~h}$, the membranes were developed using chemiluminescence (Pierce) and exposed to X-ray film.

Statistical evaluation. The data are represented as mean $\pm \mathrm{SD}$ $\mathrm{IC}_{50}$ for each NVP-ADW742 and temozolomide was defined as concentration of drug that reduces growth by $50 \%$ compared with untreated control cells and was calculated from linear transformation of dose-response curves. Data were statistically analyzed by one-way analysis of variance (ANOVA).

\section{Results}

NVP-ADW742 selectively inhibits IGF-IR-mediated proliferation. To study the effects of NVP-ADW742 on the proliferation of medulloblastoma in vitro, Daoy cells were seeded in a 96-well plate at density of $1 \times 10^{6}$ cells $/ \mathrm{ml}$. The following day, medium was changed in DMEM plus $10 \%$ FBS without (control) or with NVP-ADW742 $(0.5-50 \mu \mathrm{mol} / \mathrm{l})$. Cells were collected after $72 \mathrm{~h}$. CCK-8 assays demonstrated that IGF-IRmediated proliferation was inhibited by NVP-ADW742 with an $\mathrm{IC}_{50}$ of $11.12 \mu \mathrm{mol} / 1$ (Fig. 1).

Effects of NVP-ADW742 on cell cycle and apoptosis. To further characterize the mechanism of the anti-tumor activity of NVP-ADW742 on Daoy cells, we initially investigated whether NVP-ADW742 treatment would affect the cell cycle status. Daoy cells were synchronized in 6-well cell plates in DMEM plus $10 \% \mathrm{FBS}$, followed by the exposure to NVP-ADW742 (0.1-5 $\mu \mathrm{mol} / \mathrm{l})$ for $72 \mathrm{~h}$. Some previous studies suggested that IGF-1 could stimulate the DNA synthesis. However,
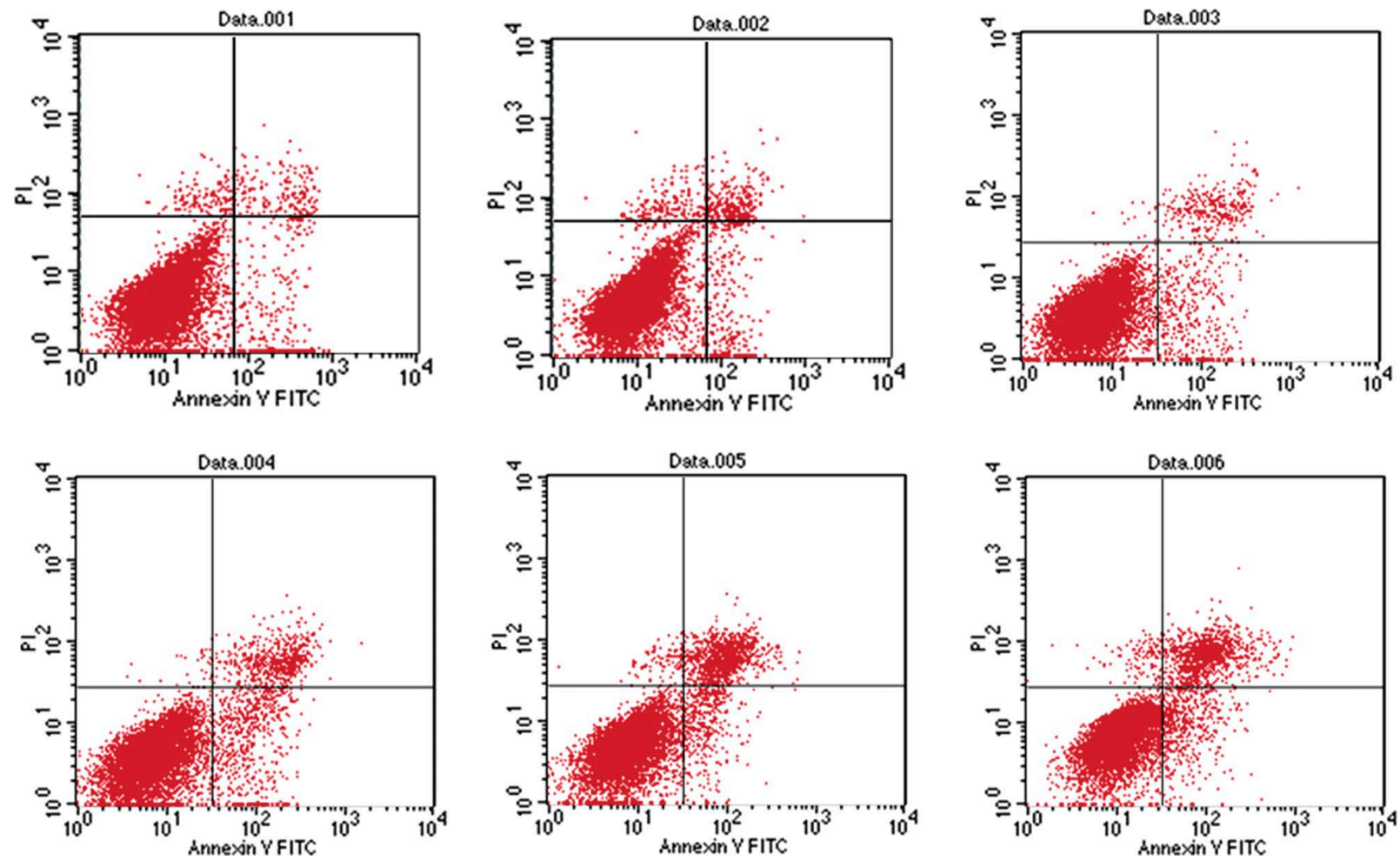

Figure 2. The effects of NVP-ADW742 treatment on apoptosis were assayed by Annexin V-FITC FACS analysis. Cells were cultured for $72 \mathrm{~h}$ in the indicated concentrations of NVP-ADW742, from 0.1 to $10 \mu \mathrm{mol} / 1$. NVP-ADW742 induced apoptosis of Daoy cells in a dose-dependent manner. The data were repeated for at least three times from different experiments $(n=3, P<0.01)$ 


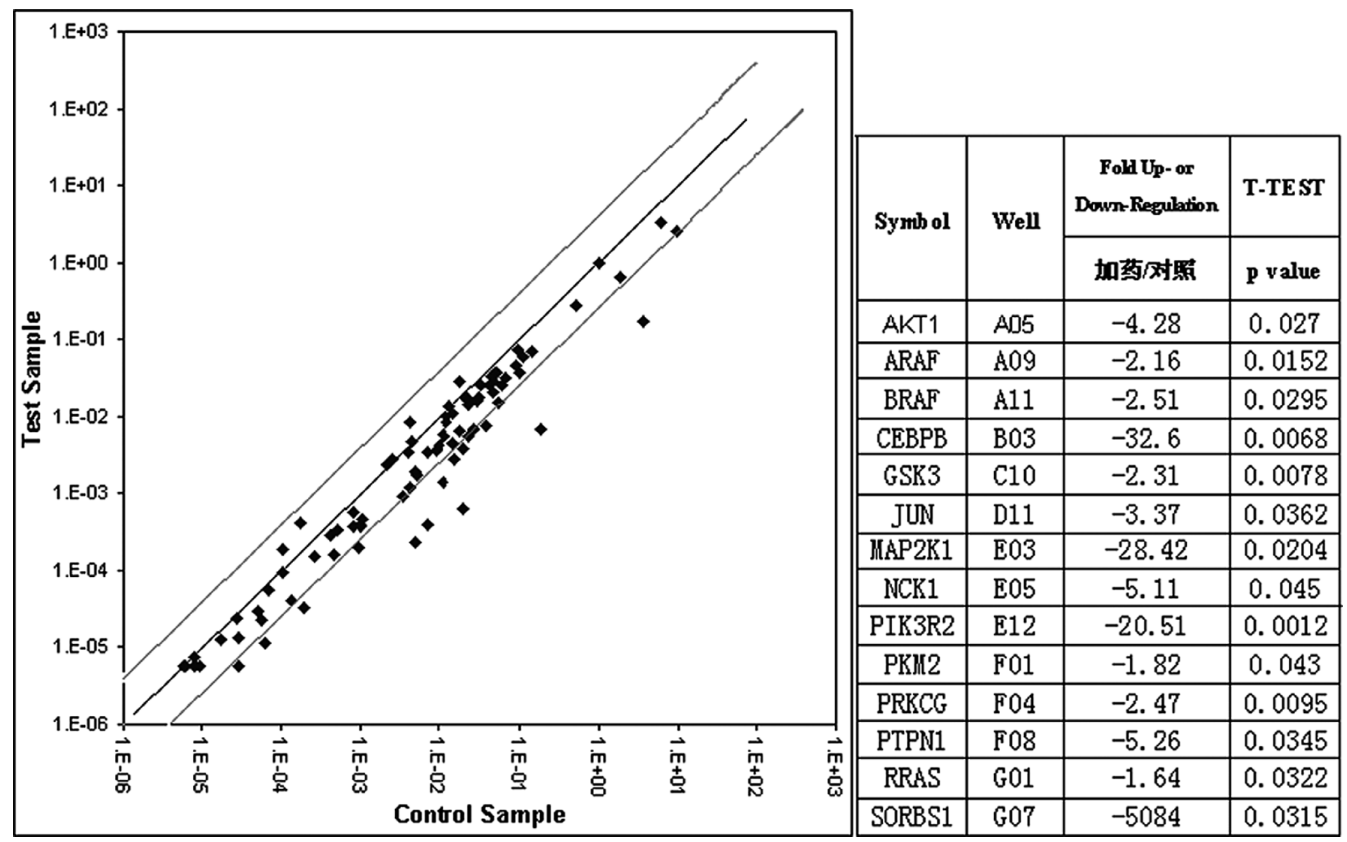

Figure 3. NVP-ADW742 selectively inhibits IGF-IR signaling pathway in mRNA level. The effects of NVP-ADW742 treatment on IGF-IR signaling pathway in mRNA level were assayed by quality PCR array. Cells were cultured for $72 \mathrm{~h}$ with/without NVP-ADW742 $\left(2 \mu\right.$ mol/l). Samples were tested by RT ${ }^{2}$ Profiler $^{\mathrm{TM}}$ PCR Array Human Insulin Signaling Pathway. Data were analyzed by $\Delta \Delta \mathrm{Ct}$ method. Quality PCR array indicated that 14 of the 89 genes tested were down-regulated in the mRNA level after NVP-ADW742 treatment, including PI3K, Akt, P38, and GSK-3 $\beta$. The experiment was performed in triplicate and repeated three times $(\mathrm{n}=3, \mathrm{P}<0.05)$.

NVP-ADW742 treatment, even at the concentration of $5 \mu \mathrm{mol} / \mathrm{l}$, did not induce discernable alternation of cell cycle in Daoy cells (data not shown). In order to determine whether the decreased viable cell numbers was due to the induction of apoptosis, Annexin V and PI staining assay was used to measure the apoptosis. NVP-ADW742 could induce the apoptosis of Daoy cells in a dose-dependent manner (Fig. 2). Thus, the anti-tumor activity of NVP-ADW742 on medulloblastoma was mainly mediated through apoptosis induction.

NVP-ADW742 selectively inhibits the IGF-IR signaling pathway. Since NVP-ADW742 is an ATP-competitive inhibitor that inhibits IGF-IR, we investigated the inhibition of NVP-ADW742 on IGF-IR signaling pathway by quality PCR array and Western blot analysis. At first, we inquired into the changes in mRNA level by quality PCR array. Cells were cultured for $72 \mathrm{~h}$ with/without NVP-ADW742 $(2 \mu \mathrm{mol} / \mathrm{l})$. Samples were tested by RT ${ }^{2}$ Profiler $^{\mathrm{TM}}$ PCR Array Human Insulin Signaling Pathway. Quality PCR array suggested that 14 of 89 genes tested were down-regulated in the mRNA level after NVP-ADW742 treatment, including PI3K, Akt, P38, and GSK-3 $\beta$ (Fig. 3). Furthermore, we focused on the differences in protein level by Western blotting. Starved cells were exposed to NVP-ADW742 $(2 \mu \mathrm{mol} / \mathrm{l})$ for $1-48 \mathrm{~h}$ in standard medium. Samples were tested by Western blotting. Western blot analysis suggested that NVP-ADW742 induced early suppression of Akt, P38 and GSK-3 $\beta$ phosphorylation, and decreased intracellular levels of PI3K, Akt, P38, GSK-3 $\beta$ and Bcl-2 (Fig. 4). Then starved cells were pretreated for $2 \mathrm{~h}$ with NVP-ADW742 $(0.5-2 \mu \mathrm{mol} / \mathrm{l})$ and then exposed to IGF-I $(10 \mathrm{ng} / \mathrm{ml})$ for $48 \mathrm{~h}$. After treated with NVP-ADW742 combined with IGF-I for $48 \mathrm{~h}$ we found again that the phosphorylation of Akt, P38 and GSK-3 $\beta$ were down-regulated and the total levels

\begin{tabular}{|c|c|c|c|c|c|c|}
\hline Time point & Oh $\quad$ lh & & $6 \mathrm{~h}$ & & & $48 \mathrm{~h}$ \\
\hline NVP-ADW742 $(\mu \mathrm{mol} / 1)$ & 22 & 2 & 2 & 2 & 2 & \\
\hline PI3K & $=$ & - & - & - & - & - \\
\hline Akt & 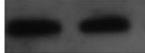 & - & $\rightarrow$ & - & - & $\because$ \\
\hline p-Akt & -- & - & & & & \\
\hline $\mathrm{P} 38$ & & & & & $=$ & \\
\hline p-P38 & - & & $7 x$ & . & & \\
\hline GSK3 $\beta$ & 0 & 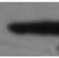 & - & - & 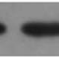 & \\
\hline p-GSK3B & 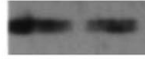 & & & & • & \\
\hline Bcl-2 & 30 & $=$ & - & $*$ & $\longrightarrow$ & \\
\hline$\beta$-actin & 5 & es & $=$ & & $=$ & \\
\hline
\end{tabular}

Figure 4. NVP-ADW742 selectively inhibits the IGF-IR signaling pathway in protein level. The effects of NVP-ADW742 treatment on IGF-IR signaling pathway in protein level were assayed by Western blotting. Starved cells were exposed to NVP-ADW742 $(2 \mu \mathrm{mol} / \mathrm{l})$ for $1-48 \mathrm{~h}$ in standard medium. As shown above, the phosphorylation of Akt, P38 and GSK-3 $\beta$ were down-regulated and the total levels of PI3K, Akt, P38, GSK-3 $\beta$ and Bcl-2 were reduced by NVP-ADW742 treatment. The data were repeated for at least three times from different experiments $(n=3, P<0.05)$.

of PI3K, Akt, P38, GSK-3 $\beta$ and Bcl-2 were reduced in a dosedependent manner (Fig. 5).

NVP-ADW742 enhances the chemosensitivity to temozolomide. Several recent studies indicated that IGF-I might contribute to the drug resistance of medulloblastoma. To 


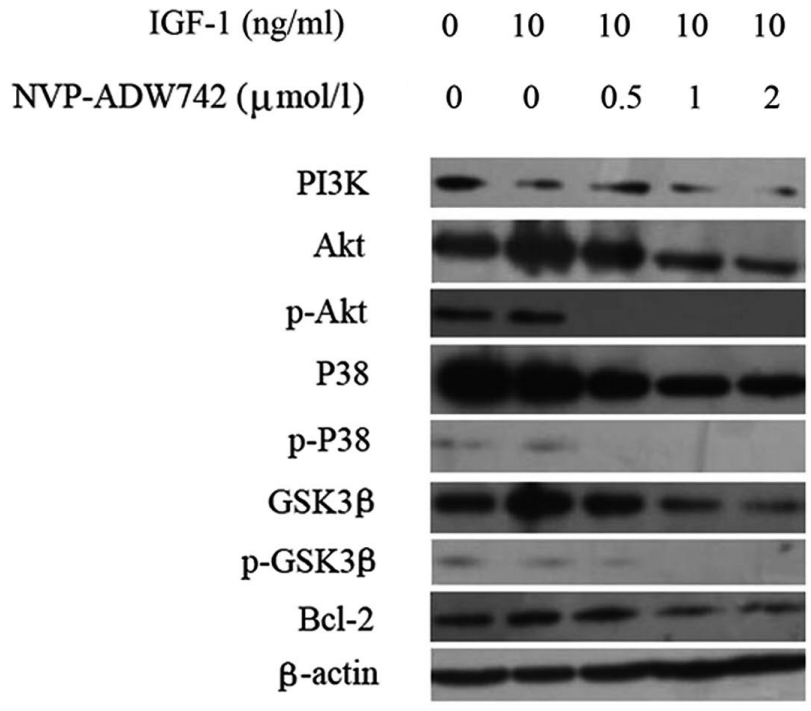

Figure 5. NVP-ADW742 selectively inhibits the IGF-IR signaling pathway in protein level. The effects of NVP-ADW742 treatment on IGF-IR signaling pathway in protein level were assayed by Western blotting. Starved cells were pretreated for $2 \mathrm{~h}$ with NVP-ADW742 $(0.5-2 \mu \mathrm{mol} / \mathrm{l})$ and then exposed to IGF-I $(10 \mathrm{ng} / \mathrm{ml})$ for $48 \mathrm{~h}$. As shown, the phosphorylation of Akt, P38 and GSK-3 $\beta$ were down-regulated and the total levels of PI3K, Akt, P38, GSK-3 $\beta$, C/EBP $\beta$ and Bcl-2 were reduced by NVP-ADW742 treatment in a dose-dependent manner. The data were repeated for at least three times from different experiments $(\mathrm{n}=3, \mathrm{P}<0.05)$.

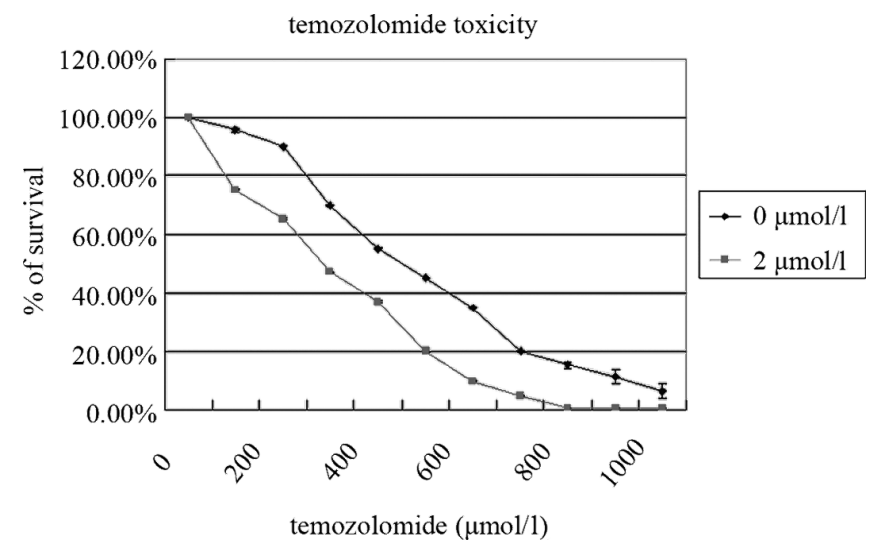

Figure 6. NVP-ADW742 enhances the chemosensitivity to temozolomide Daoy cells were seeded in a 96-well plate at density of $1 \times 10^{6}$ cells $/ \mathrm{ml}$. The following day, medium was changed in DMEM plus 10\% FBS without (control) or with NVP-ADW742 $(2 \mu \mathrm{mol} / 1)$ combined with temozolomide $(0-1000 \mu \mathrm{mol} / \mathrm{l})$. Cells were collected after $72 \mathrm{~h}$. The CCK- 8 assay was performed successively. CCK-8 assays demonstrated that $\mathrm{IC}_{50}$ of Daoy to temozolomide was $452.12 \mu \mathrm{mol} / 1$, and $\mathrm{IC}_{50}$ of Daoy to temozolomide combined with NVP-ADW742 $(2 \mu \mathrm{mol} / \mathrm{l})$ was $256.81 \mu \mathrm{mol} / 1$. The results are the means $\pm \mathrm{SD}$ of three separate experiments and each sample was performed in triplicate $(\mathrm{n}=3, \mathrm{P}<0.01)$

examine the possible involvement of IGF-I R signaling pathway in the temozolomide resistance, we investigated whether NVP-ADW742 could enhance the chemosensitivity of Daoy to temozolomide. Daoy cells were seeded in a 96-well plate at density of $1 \times 10^{6}$ cells $/ \mathrm{ml}$. The following day, medium was changed in DMEM plus $10 \%$ FBS without (control) or with NVP-ADW742 $(2 \mu \mathrm{mol} / \mathrm{l})$ combined with temozolomide (0-1000 $\mu \mathrm{mol} / \mathrm{l})$. Cells were collected after 72 h. CCK-8 assays demonstrated that $\mathrm{IC}_{50}$ of Daoy to temozolomide was $452.12 \mu \mathrm{mol} / 1$, and $\mathrm{IC}_{50}$ of Daoy to temozolomide combined with NVP-ADW742 (2 $\mu \mathrm{mol} / \mathrm{l})$ was $256.81 \mu \mathrm{mol} / 1$ (Fig. 6). Furthermore, the effect of NVP-ADW742 combined with temozolomide on cell cycle and apoptosis was tested. Daoy cells were synchronized in 6-well cell plates in DMEM plus $10 \%$ FBS, followed by the exposure to temozolomide $(100 \mu \mathrm{mol} / \mathrm{l})$ with or without NVP-ADW742 $(2 \mu \mathrm{mol} / \mathrm{l})$ for $72 \mathrm{~h}$. G phase arrested was found in both the group temozolomide alone and the group temozolomide combined with NVP-ADW742 (Fig. 7). NVP-ADW742 enhanced cell apoptosis of Daoy to temozolomide from $16.18 \pm 2.47 \%$ to $23.20 \pm 2.80 \%$ (Fig. 8 ). To investigate the mechanism of IGF-I R signaling pathway in the temozolomide resistance, we measured the protein profile by Western blotting. Temozolomide might activate the phosphorylation of Akt, P38 and GSK-3 $\beta$, and the activation of PI3K, Akt, P38 and GSK-3 $\beta$ were inhibited by NVP-ADW742 (Fig. 9). The enhancement in sensitivity to chemotherapy tightly correlates with inhibition of PI3K-Akt activation by NVP-ADW742.

\section{Discussion}

Recent advances in understanding the molecular mechanisms involved in the control of proliferation and differentiation of medulloblastoma showed that the function of the insulin-like growth factor system in the control of growth (10). Several reports show that the IGF-IR signaling system is highly activated in medulloblastoma cell lines. IGF-IR signaling pathway arose early in evolution, possibly as a regulator of cellular proliferation. The role of IGF-IR signaling in controlling rates of cell renewal has led to this regulatory system to both ageing and neoplasia. IGF-IR is a tetrameric transmembrane receptor tyrosine kinase composed of two $\alpha$ and two $\beta$ subunits linked by disulfide bonds (11). Phosphorylation of these tyrosine residues is necessary for activation of the receptor kinase. After autophosphorylation, the receptor kinase phosphorylates intracellular proteins, such as the insulin receptor (IR) substrate-1 and Shc, which enable activation of the phosphatidylinositol 3-kinase (PI3K) and the mitogen-activated protein kinase signaling pathways (12). IGF-1R plays an important role in transformation and proliferation of malignant cells. The IGF-1R is also important for preventing apoptosis and maintaining the malignant phenotype of tumor cells, and is involved in tumor cell protection against chemotherapy. On the basis of the pivotal role of IGF-1R in malignant cells, it becomes increasingly evident that IGF- $1 \mathrm{R}$ is a promising target for anticancer therapy. A direct strategy to interfere with IGF-1R activity is to induce selective inhibition of its tyrosine kinase. In this study, we investigated the therapeutic potential of the novel, selective inhibitor of IGF-IR kinase, NVP-ADW742, against medulloblastoma.

NVP-ADW742 is a pyrrolo(2,3-d)pyrimidine derivative that binds in the ATP binding pocket of the IGF-IR and inhibits its in vitro kinase activity with an $\mathrm{IC}_{50}$ of $0.1-0.2 \mu \mathrm{mol} / 1$ (13), the selective kinase inhibitor NVP-ADW742 has in vitro activity against diverse tumor cell types (particularly multiple myeloma). Regarding hematopoietic malignancies, multiple myeloma (MM) is highly sensitive to the IGF-1R specific inhibitor NVP-ADW742. This small molecular weight inhibitor can rapidly shut down PI3K/Akt signaling and induce cell 


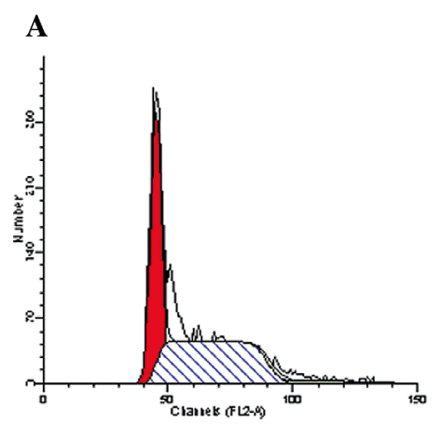

Control

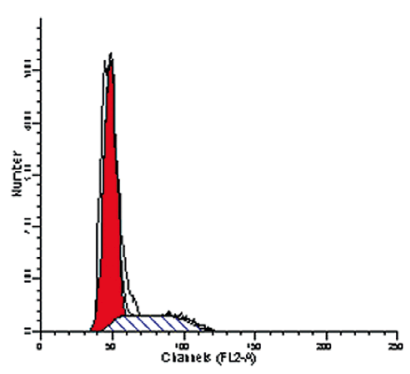

$\mathrm{TMZ}$

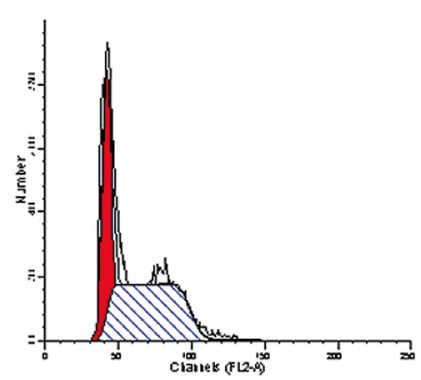

NVP-ADW742

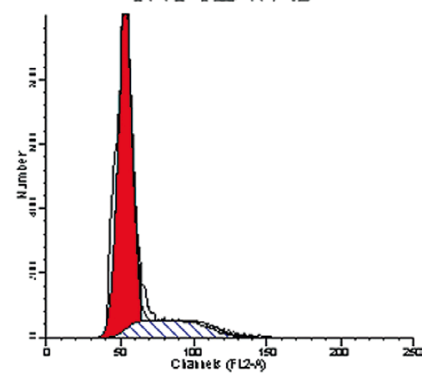

NVP-ADW742+TMZ

B

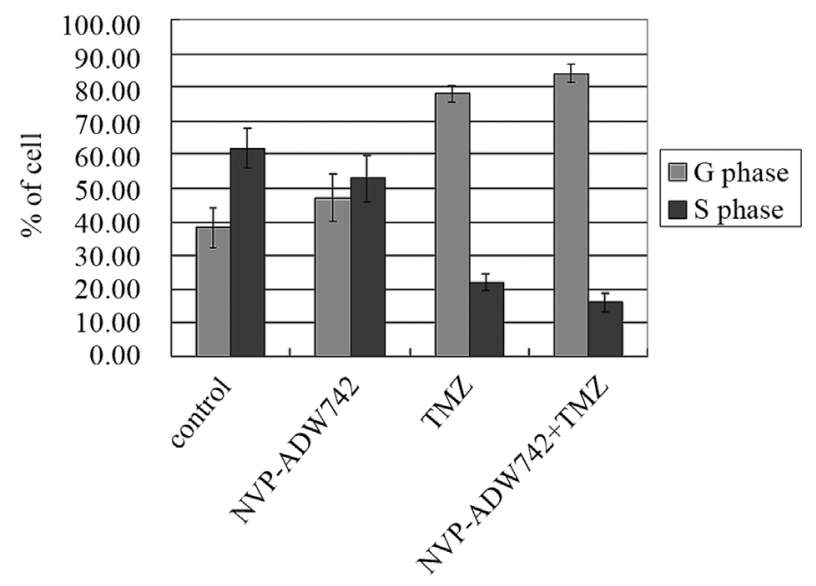

Figure 7. The effect of NVP-ADW742 combined with temozolomide on cell cycle. Daoy cells were synchronized in 6-well cell plates in DMEM plus $10 \% \mathrm{FBS}$, followed by the exposure to temozolomide $(100 \mu \mathrm{mol} / \mathrm{l})$ with or without NVP-ADW742 (2 $\mu \mathrm{mol} / 1)$ for $72 \mathrm{~h}$ (A). The effects of NVPADW742 treatment on cell cycle status were assayed by FACS analysis (B). $\mathrm{G}$ phase arrested was found in both the group temozolomide alone and the group temozolomide combined with NVP-ADW742. The data were repeated for at least three times from different experiments $(n=3, P<0.01)$.

cycle arrest and apoptosis of MM cells (14,15). NVP-ADW742 monotherapy or its combination with cytotoxic chemotherapy had significant anti-tumor activity, providing in vivo proof of principle for therapeutic use of selective IGF-1R inhibitors in cancer. In our study, $\mathrm{IC}_{50}$ of Daoy to temozolomide was decreased from 452.12 to $256.81 \mu \mathrm{mol} / \mathrm{l}$ combined with NVP-ADW742 $(2 \mu \mathrm{mol} / \mathrm{l})$. NVP-ADW742 enhanced cell apoptosis from $16.18 \pm 2.47 \%$ to $23.20 \pm 2.80 \%$. G phase arrested was also found in both the group temozolomide alone and the group temozolomide combined with NVP-ADW742. NVP-ADW742 enhanced the chemosensitivity of Daoy to temozolomide.

IGF-IR has become an attractive target for novel cancer therapeutics based on its role of promoting tumor growth
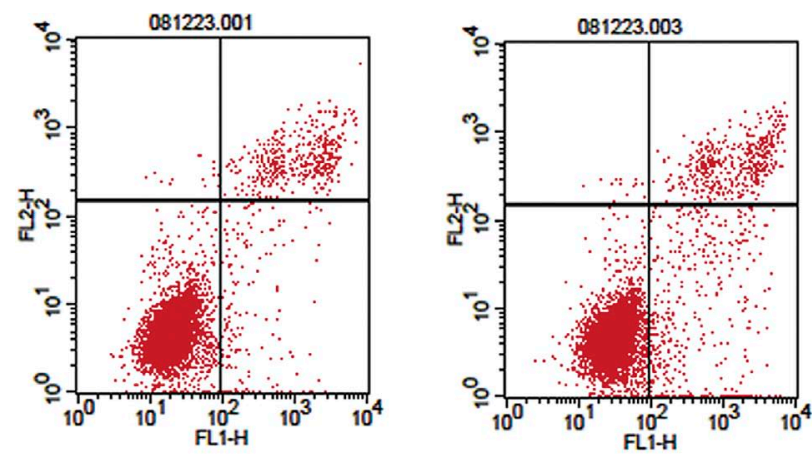

\section{Control}

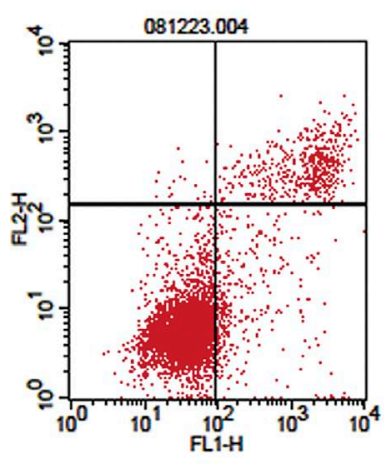

TMZ
NVP-ADW742

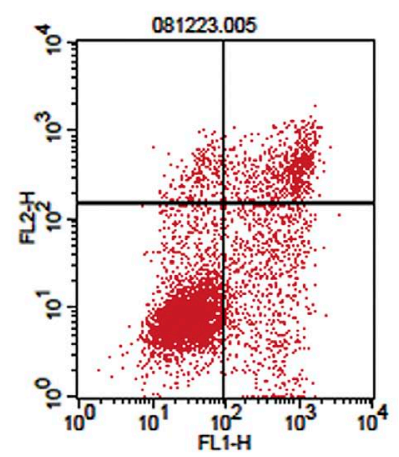

NVP-ADW742+TMZ

Figure 8. The effect of NVP-ADW742 combined with temozolomide on apoptosis was assayed by Annexin V-FITC FACS analysis. Daoy cells were synchronized in 6-well cell plates in DMEM plus $10 \%$ FBS, followed by the exposure to temozolomide $(100 \mu \mathrm{mol} / \mathrm{l})$ with or without NVP-ADW742 $(2 \mu \mathrm{mol} /)$ for $72 \mathrm{~h}$. NVP-ADW742 enhanced cell apoptosis of Daoy to temozolomide from $16.18 \pm 2.47 \%$ to $23.20 \pm 2.80 \%$. The data were repeated for at least three times from different experiments $(n=3, P<0.01)$.

\section{TMZ $(100 \mu \mathrm{mol} / \mathrm{l})$ \\ NVP-ADW742 $(2 \mu \mathrm{mol} / \mathrm{l})$}

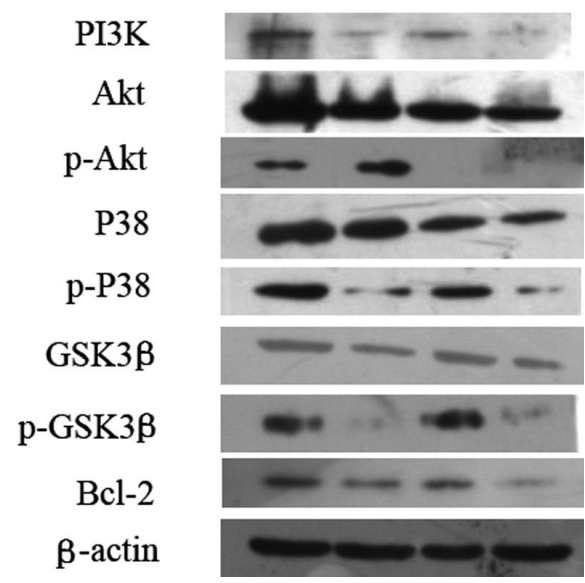

Figure 9. NVP-ADW742 enhances the chemosensitivity to temozolomide by inhibition of PI3K-Akt activation. To investigate the mechanism of IGF-I R signaling pathway in the temozolomide resistance, we measured the protein profile by Western blotting. Daoy cells were synchronized in 6-well cell plates in DMEM plus $10 \%$ FBS, followed by the exposure to temozolomide $(100 \mu \mathrm{mol} / \mathrm{l})$ with or without NVP-ADW742 $(2 \mu \mathrm{mol} / \mathrm{l})$ for $72 \mathrm{~h}$. Temozolomide might activate the phosphorylation of Akt, P38 and GSK-3 $\beta$, and the activation of PI3K, Akt, P38 and GSK-3 $\beta$ were inhibited by NVP-ADW742. 
and survival. It is a potent regulator of cellular survival and apoptosis predominantly by activating the phosphatidylinositol 3-kinase (PI3K)-Akt intracellular signaling pathway and its divergent downstream signaling cascades, such as P38, GSK-3 $\beta(16,17)$. IGF-I has been shown to directly stimulate the expression of Bcl-2 and Bcl-XL and suppresses the expression of Bax, resulting in inhibition of apoptosis $(18,19)$. To figure out the mechanism of IGF-I R signaling pathway in the temozolomide resistance, we examined the effects of NVP-ADW742 treatment on IGF-1R signaling pathway. Similar to previous studies (20-23), quality PCR array suggested that 14 genes were down-regulated in the mRNA level after NVP-ADW742 treatment, including PI3K, Akt, P38, GSK-3 $\beta$ and so on. The phosphorylation of Akt, P38 and GSK-3 $\beta$ were down-regulated and the total levels of PI3K, Akt, P38, GSK-3 $\beta$ and Bcl-2 were reduced by NVP- ADW742 treatment. NVP- ADW742 inhibited the phosphorylation of Akt, P38 and GSK-3 $\beta$, and decreased the total levels of PI3K, Akt, P38, GSK-3 $\beta$ and Bcl-2 in a dose-dependent manner. Temozolomide might activate the phosphorylation of Akt, P38 and GSK-3 $\beta$, and the activation of PI3K, Akt, P38 and GSK-3 $\beta$ were inhibited by NVP-ADW742. Based on its combined effects on mitogenic and anti-apoptotic signaling, IGF-IR has been implicated in the establishment and maintenance of the transformed phenotype in many cellular backgrounds. IGF-IR is a very potent stimulator of PI3K-Akt signaling in medulloblastoma in terms of both the degree of activation and the length of time the pathway remains activated after stimulation. Growth stimulated by IGF-IR is largely mediated by PI3K-Akt signaling, which also enhances resistance to the apoptotic effect of chemotherapy (24). Thus, inhibition of IGF-IR signaling could be an important novel therapeutic approach in medulloblastoma. The enhancement in sensitivity to chemotherapy tightly correlates with inhibition of PI3K-Akt activation by NVP-ADW742.

In summary, our study supports the concept that IGF-IR signaling plays an important role in proliferation and apoptosis of medulloblastoma. In addition, we provide in vitro evidence that NVP-ADW742 enhances the chemosensitivity of Daoy to temozolomide, as a potent anti-tumor agent highly selective against IGF-IR.

\section{Acknowledgements}

This study was supported by National Nature Science Foundation of China (No. 30772240) and Zhejiang Provincial Natural Science Foundation of China (No. Y2080297).

\section{References}

1. Crawford JR, MacDonald TJ and Packer RJ: Medulloblastoma in childhood: new biological advances. Lancet Neurol 6: 1073-1085, 2007.

2. Rossi A, Caracciolo V, Russo G, Reiss K and Giordano A: Medulloblastoma: from molecular pathology to therapy. Clin Cancer Res 14: 971-976, 2008.

3. Patti R, Reddy CD, Geoerger B, Grotzer MA, Raghunath M, Sutton LN and Phillips PC: Autocrine secreted insulin-like growth factor-I stimulates MAP kinase-dependent mitogenic effects in human primitive neuroectodermal tumor/medulloblastoma. Int J Oncol 16: 577-584, 2000

4. Wang JY, Del Valle L, Gordon J, Rubini M, Romano G, Croul S, Peruzzi F, Khalili K and Reiss K: Activation of the IGF-IR system contributes to malignant growth of human and mouse medulloblastomas. Oncogene 20: 3857-3868, 2001.
5. Del Valle L, Enam S, Lassak A, Wang JY, Croul S, Khalili K and Reiss K: Insulin-like growth factor I receptor activity in human medulloblastomas. Clin Cancer Res 8: 1822-1830, 2002.

6. Sell C, Baserga R and Rubin R: Insulin-like growth factor I (IGF-I) and the IGF-I receptor prevent etoposide-induced apoptosis. Cancer Res 55: 303-306, 1995.

7. Morrione A, Romano G, Navarro M, Reiss K, Valentinis B, Dews M, Eves E, Rosner MR and Baserga R: Insulin-like growth factor I receptor signaling in differentiation of neuronal H19-7 cells. Cancer Res 60: 2263-2272, 2000.

8. Baserga R: The insulin-like growth factor I receptor: a key to tumor growth? Cancer Res 55: 249-252, 1995.

9. Hewish M, Chau I and Cunningham D: Insulin-like growth factor 1 receptor targeted therapeutics: novel compounds and novel treatment strategies for cancer medicine. Recent Pat Anticancer Drug Discov 4: 54-72, 2009.

10. Reiss K: Insulin-like growth factor-I receptor - a potential therapeutic target in medulloblastomas. Expert Opin Ther Targets 6: 539-544, 2002.

11. Ullrich A and Schlessinger J: Signal transduction by receptors with tyrosine kinase activity. Cell 61: 203-212, 1990.

12. Navarro $M$ and Baserga R: Limited redundancy of survival signals from the type 1 insulin-like growth factor receptor. Endocrinology 142: 1073-1081, 2001.

13. Garcia-Echeverria C: Medicinal chemistry approaches to target the kinase activity of IGF-1R. IDrugs 9: 415-419, 2006.

14. Mitsiades CS, Mitsiades N, Poulaki V, Schlossman R, Akiyama M, Chauhan D, Hideshima T, Treon SP, Munshi NC, Richardson PG and Anderson KC: Activation of NF-kappaB and upregulation of intracellular anti-apoptotic proteins via the IGF-1/Akt signaling in human multiple myeloma cells: therapeutic implications. Oncogene 21: 5673-5683, 2002.

15. Morgan GJ, Krishnan B, Jenner M and Davies FE: Advances in oral therapy for multiple myeloma. Lancet Oncol 7: 316-325, 2006.

16. Kulik G, Klippel A and Weber MJ: Antiapoptotic signalling by the insulin-like growth factor I receptor, phosphatidylinositol 3-kinase and Akt. Mol Cell Biol 17: 1595-1606, 1997.

17. Urbanska K, Trojanek J, Del Valle L, Eldeen MB, Hofmann F Garcia-Echeverria C, Khalili K and Reiss K: Inhibition of IGF-I receptor in anchorage-independence attenuates GSK-3beta constitutive phosphorylation and compromises growth and survival of medulloblastoma cell lines. Oncogene 26: 2308-2317, 2007.

18. Parrizas $M$ and LeRoith D: Insulin-like growth factor-1 inhibition of apoptosis is associated with increased expression of the bcl-xL gene product. Endocrinology 138: 1355-1358, 1997.

19. Minshall C, Arkins S, Straza J, Conners J, Dantzer R, Freund GG and Kelley KW: IL-4 and insulin-like growth factor-I inhibit the decline in Bcl-2 and promote the survival of IL-3-deprived myeloid progenitors. J Immunol 159: 1225-1232, 1997.

20. Tanori M, Santone M, Mancuso M, Pasquali E, Leonardi S, Di Majo V, Rebessi S, Saran A and Pazzaglia S: Developmental and oncogenic effects of insulin-like growth factor-I in Ptc1 ${ }^{+/}$ mouse cerebellum. Mol Cancer 9: 53, 2010.

21. Martins AS, Mackintosh C, Martín DH, Campos M, Hernández T, Ordóñez JL and De Alava E: Insulin-like growth factor I receptor pathway inhibition by ADW742, alone or in combination with imatinib, doxorubicin, or vincristine, is a novel therapeutic approach in Ewing tumor. Clin Cancer Res 12: 3532-3540, 2006.

22. Warshamana-Greene GS, Litz J, Buchdunger E, GarciaEcheverria C, Hofmann F and Krystal GW: The insulin-like growth factor-I receptor kinase inhibitor, NVP-ADW742, sensitizes small cell lung cancer cell lines to the effects of chemotherapy. Clin Cancer Res 11: 1563-1571, 2005.

23. Warshamana-Greene GS, Litz J, Buchdunger E, Hofmann F, Garcia-Echeverria C and Krystal GW: The insulin-like growth factor-I (IGF-I) receptor kinase inhibitor NVP-ADW742, in combination with STI571, delineates a spectrum of dependence of small cell lung cancer on IGF-I and stem cell factor signaling. Mol Cancer Ther 3: 527-535, 2004.

24. Mitsiades CS, Mitsiades NS, McMullan CJ, Poulaki V, Shringarpure R, Akiyama M, Hideshima T, Chauhan D, Joseph M, Libermann TA, Garcia-Echeverria C, Pearson MA, Hofmann F, Anderson KC and Kung AL: Inhibition of the insulin-like growth factor receptor-1 tyrosine kinase activity as a therapeutic strategy for multiple myeloma, other hematologic malignancies, and solid tumors. Cancer Cell 5: 221-230, 2004. 